\title{
Repetition of Less Common Sound Patterns: A Unique Relationship to Young Children's Phonological Awareness and Word Reading
}

\author{
Jamie L. Metsala \\ Mount Saint Vincent University \\ 166 Bedford Highway, Halifax, NS B3M 2J6, Canada \\ Tel: 1-902-457-6357Ｅ-mail: jamie.metsala@msvu.ca
}

Received: April 19, $2011 \quad$ Accepted: June 6, $2011 \quad$ doi:10.5539/ijel.v1n2p3

This research was supported by a Natural Sciences and Engineering Research Council of Canada Discovery Grant.

\begin{abstract}
The current study examined predictors of concurrent phonological awareness in 95 Grade 1 children and of reading achievement 5 months later. Of primary interest was whether the repetition of nonwords with less versus more common sound patterns was a better predictor of these variables. Only the repetition of nonwords low in wordlikeness predicted unique variance in concurrent phonological awareness after measures of phonological memory and vocabulary. Similarly, nonword repetition for words low in wordlikeness accounted for unique variance in later reading after measures of fall reading, phonological memory, vocabulary, and phonological awareness. A fall phonological representations factor was directly related to later reading achievement. Results are discussed within a framework for which the representation of less common sound sequences has a robust relationship to reading acquisition, and for which awareness of the phonemic structure of language may be reducible to the representation of phonological information in lexical memory.
\end{abstract}

Keywords: Phonological awareness, Phonological representations, Lexical development, Reading acquisition

\section{Introduction}

One focus of reading-related research has been on the role of phonological representations in the emergence of young children's phonological awareness (e.g., Fowler, 1991; Metsala, 1999; Rvachew, 2006; Swan \& Goswami, 1997) and reading acquisition (e.g., McBride-Chang, Wagner \& Chang, 1997; Wessling \& Reitsma, 2001), and in relation to the phonological core deficit in reading disabilities (e.g., Boada \& Pennington, 2006; Elbro, 1996; Elbro \& Jensen, 2005). The present study examined the relationship between measures indexing phonological representations, phonological awareness and reading in Grade 1 children. The term "phonological representation" is used here to refer to the word-level phonological form or information stored in lexical memory. In prevalent models of adult spoken word recognition, lexical representations are made up of sequences of constituent phonemes and the mental lexicon is organized in terms of phonemic-similarity neighborhoods (e.g., Luce \& Pisoni, 1998). These similarity neighborhoods are frequently defined as the number of words that differ from the target word by a one phoneme substitution, addition or deletion (e.g., Vitevitch \& Luce, 1998). Phonological awareness is the ability to explicitly access and/or manipulate the phonological units in spoken words, such as onsets, rimes, and phonemes.

\subsection{Associations of Phonological Representations and Vocabulary with Phonological Awareness and Reading}

In general, studies have supported associations between tasks used to index phonological representations and concurrent or subsequent phonological awareness and/or word reading in studies of pre-school children (e.g., Claessen, Heath, Fletcher, Hogben, \& Leitão 2008), normally achieving school-age children (e.g., Metsala, Stavrinos, \& Walley, 2009), children with reading disabilities or language impairments (e.g., Elbro \& Jensen, 2005; Rvachew, 2006), children "at risk" for reading disabilities (e.g., Elbro, Borstrom \& Peterson, 1998), and second language learners (e.g., Chiappe, Glaeser, \& Ferko, 2007). For example, 11-13 year-old children with dyslexia performed more poorly than age and reading-level comparison groups on a composite variable tapping implicit phonological representations and this implicit factor accounted for $63 \%$ of the overlapping variance between phonological awareness and reading (Boada \& Pennington, 2006). Sénéchal, Oulette, \& Young (2004) reported that articulation and speech perception for a specific phoneme each predicted unique variance in later 
phonological awareness for that same phoneme for typically developing preschoolers (see also Thomas \& Sénéchal, 2004). Individual differences in the specificity of lexical representations predicted growth in phonological awareness in young children at-risk for dyslexia (Elbro et al., 1998) and training aimed at improving phonological representations resulted in increased phonological awareness for the same lexical items (Elbro \& Jensen, 2005).

Individual and group differences on such tasks have been variously explained in terms of the amount of stored phonetic detail or the robustness and differentiation of the individual phonemes that make up lexical items (e.g., Edwards, Beckham, \& Munson, 2004; Elbro et al., 1998; Metsala, 1999; Swan \& Goswami, 1997). Studies have reported either a direct relationship between measures of representational quality and word reading (e.g., Chiappe et al, 2007; Metsala, 1997b) or have found this relationship to be fully mediated by phonological awareness (e.g., Bruno et al., 2007; McBride-Chang et al., 1997; Metsala et al., 2009). One goal of this study was to examine whether a fall measure of phonological representations accounted for direct variance in later word-level reading achievement.

The association of vocabulary to phonological awareness also bears on the issue of the role of lexical representations in reading acquisition and was examined in the current study. Studies have generally found that vocabulary knowledge (measured by receptive or expressive tasks) contributes unique variance to concurrent and/or subsequent phonological awareness (e.g., Carroll \& Snowling, 2001; Cooper, Roth, Speece, Schatschneider, 2002; Foy \& Mann, 2001; 2003; Lonigan, Burgess, \& Anthony, 2000; Metsala, 1999; Sénéchal \& LeFevre, 2002; Silvén, Niemi \& Voeten, 2002; cf. Carroll, Snowling, Stevenson, \& Hulme, 2003; Roberts, 2005). One Finnish study found that vocabulary measures at 3.5 years were strongly associated with later phonological awareness and that effects of the Home Learning Environment on later phonological awareness were indirect through their relationship with vocabulary (Torppa et al., 2007; see also, Chaney, 1994; Cooper et. al. 2002; Sénéchal \& LeFevre, 2002). McDowell, Lonigan and Goldstein (2007) found that for a sample of 700, 2- to 5-year-olds, measures of speech sound accuracy (word and nonword repetition) and vocabulary contributed unique variance to growth in phonological awareness, similar to findings for children with speech sound disorders (Rvachew, 2006; Rvachew \& Grawburg, 2006). More direct support for a causal link between vocabulary growth and phonological awareness comes from Lonigan's (2007) report that a group of preschoolers receiving a vocabulary-based intervention improved on phonological awareness tasks compared to a control group.

One proposal has been that lexical-level phonemic organization emerges as a result of vocabulary growth (e.g., Bonte and Blomert, 2004; Jusczyk, 1993; 1995; Munson, Edwards, \& Beckman, 2005; Storkel, 2002; Walley, 1993; but see for example, Swingly \& Aslin, 2002). In turn, this reorganization with vocabulary growth is proposed to lead to the availability of the phonemic units in spoken language required for awareness tasks (e.g., Fowler, 1991; Metsala \& Walley, 1998; Walley 1993; see also Metsala et al., 2009; Smith, McGregor \& Demille, 2006; Schwarz, Burnhan, \& Bowey, 2006; for review see Metsala, 2011). In the current study, vocabulary was examined as a contributor to phonological awareness and reading acquisition within this framework for which it is intimately linked to the development of phonological representations.

\subsection{Nonword Repetition and Reading Ability}

Nonword repetition deficits have been found for children with reading disabilities (e.g., Brady, Shankweiler \& Mann, 1983; Catts, Adlof, Hogan, \& Weismer, 2005; De Bree, Rispens, \& Gerrits, 2007; Roodenrys \& Stokes, 2001; Snowling, 1981) and for pre-school children at risk for reading disabilities (e.g., Carroll \& Snowling, 2004; De Bree et al., 2007; but see Gijsel, Bosman, \& Verhoeven, 2006). DeBree and colleagues (2007) suggested that nonword repetition difficulties may be a "marker and a precursor of literacy problems" (p.940) based on findings that pre-school children at-risk for dyslexia and a group of children with dyslexia performed more poorly than comparison groups on nonword repetition tasks and that $56 \%$ of the at-risk group scored more than 1 SD below the mean of the comparison group (see also Smith, Pennington, Boada, \& Shilberg, 2005).

Studies of reading related abilities have established that phonological memory, phonological awareness, and serial naming are related, latent phonological processes that are stable over the early elementary school years (Torgesen \& Burgess, 1998; Wagner, Torgesen, Laughon, Simmons, \& Rashotte, 1993; Wagner, Torgesen, \& Rashotte, 1994). Although nonword repetition was not used in these particular studies, it has sometimes been included as one indicator of phonological memory and variance associated with word decoding ability largely overlaps with other phonological processes (e.g., Anthony, Williams, McDonald, \& Francis 2007; Barbosa, Miranda, Santos, \& Bueno, 2009; De Jong \& van der Leij, 1999). For example, De Jong \& van der Leij (1999) found that kindergarten nonword repetition was moderately correlated with grade 1 and 2 word and pseudoword reading, but the phonological memory factor did not predict unique variance in later reading ability; however, the stability of the verbal working memory factor was complicated because "the nonword repetition test was not a pure indicator of this factor" ( $\mathrm{p} .461)$. 
Alternatively, researchers have considered nonword repetition as an indicator of the quality of phonological representations (e.g., Carroll \& Snowling, 2004; Foy \& Mann, 2001; Wesseling \& Reitsma, 2001; see also, Coady \& Evans, 2008). Several findings support the connection between lexical representation and nonword repetition that underlie this approach: children repeat wordlike nonwords more accurately than less wordlike nonwords (e.g., Gathercole, 1995; Gathercole, Willis, Emslie, \& Baddeley, 1991); children repeat nonwords with a lexical unit better than those without a lexical unit (Dollaghan, Biber, \& Campbell, 1993, 1995) and for longer nonwords, repeat constituent word-syllables better than nonword-syllables (Metsala \& Chisholm, 2010); children's repetition accuracy is better for nonwords containing sequences higher versus lower in phonotactic probability (e.g., Edwards et al., 2004; Munson et al., 2005a) and for longer nonwords, better for constituent syllables from dense versus sparse lexical neighborhoods (Metsala \& Chisholm, 2010). In a recent review of research, Coady and Evans (2008) suggested that, "Because repetition accuracy depends on lexical and sublexical properties, the NRT [nonword repetition task] can be used to examine the structural properties of the lexicon in both children with NL [normal language] and with SLI [specific language impairments]" (p.1.). Nonword repetition was used in the current study as a measure of phonological representations. One question addressed whether within a sample of normally achieving children, groups differing on nonword repetition in the fall would show poorer reading after 5 months of critical first-grade reading instruction.

\subsection{Nonword Repetition and Vocabulary}

One account of the robust relationship reported in the literature between nonword repetition and vocabulary is that with increasing vocabulary knowledge segments and sequences of segments in lexical representations become more autonomous, robust, or familiar (e.g., Munson et al., 2005a) allowing these to be better arranged and/or "chunked" in the construction and maintenance of the nonword representation (e.g., Bowey, 2001; 2006; Edwards et al., 2004; Jones, Gobet \& Pine, 2007; Metsala, 1999; Metsala \& Chisholm, 2008; Munson et al., 2005a; Munson, Kurtz \& Windsor, 2005; see also Snowling, Chiat, \& Hulme, 1991). Jones et al. (2007) simulated commonly observed effects on children's nonword repetition without invoking individual differences in phonological memory capacity. Rather differences in phonological knowledge associated with vocabulary accounted for variability in nonword repetition performance across age, wordlikeness, and nonword lengths. This is consistent with findings that increases in ESL children's nonword repetition and in young children's memory span result as a function of increasing language abilities even as phonological memory capacity remains invariant (French \& O'Brien 2008; Ottem, Lian \& Karlson, 2007). Indeed, Munson (2006) has suggested that one point researchers agree upon is that nonword repetition and vocabulary learning are related due to their reliance on phonological representations. It is within this framework that the shared variance between nonword repetition and vocabulary was used as an index of phonological representations. The current study examined whether defined in this manner, each of fall phonological representations and phonological awareness contributed unique variance to later reading achievement in Grade 1 children.

\subsection{Uncommon Sound Patterns and a Robust Relationship to Reading Acquisition}

One proposal has been that the salience of phonemes in lexical representations may increase as areas of the mental lexicon become more crowded (e.g., Storkel, 2002; Walley, 1993). Empirical support for this proposal includes findings that young children's similarity judgments are more consistently based on phoneme-similarity for words from dense versus sparse neighborhoods (Storkel, 2002) and phonological awareness has been found to be better for words from dense versus sparse lexical neighborhoods (e.g., DeCara \& Goswami, 2003; Metsala, 1999). Similarly, for measures of spoken word recognition, developmental differences are least pronounced for words from dense neighborhoods (e.g., Garlock, Walley \& Metsala, 2001; Metsala, 1997a). In relation to nonword repetition more specifically, children's accuracy increases for multisyllabic words with high versus low frequency two-phoneme segments (e.g., Edwards et al., 2004; Munson et al, 2005a; 2005b) and for constituent syllables from dense versus sparse neighborhoods (Metsala \& Chisholm, 2010). In both of these studies, the magnitude of the high frequency/density advantage diminished for children with greater vocabulary knowledge (see also Masterson, Laxon, Carnegie, Wright, \& Horslen, 2005).

Phonemic representation and/or organization for less dense areas of the mental lexicon appears to undergo prolonged development and thus processing of less common sound sequences may provide a more sensitive measure of individual differences in lexical representations. In turn, processing of these sequences may be more strongly related to phonological awareness and reading acquisition. Previous research measuring spoken recognition for words from sparse neighborhoods supports this proposal. Metsala et al. (2009; see also Garlock et al., 2001) found that spoken word recognition for words from sparse neighborhoods predicted later phonological awareness and that children poorer on speech recognition tasks for these words in Year 1 had poorer word reading in Year 2. An earlier study had found that a spoken word recognition deficit in children with reading disabilities was limited to words from sparse neighborhoods and recognition of these words was predictive of reading ability in a group of 7-year-olds (Metsala, 1997b). The current study examined whether the 
proposal of a special relationship between processing less common sound patterns and reading acquisition can be generalized to a nonword repetition task.

In the current study, wordlikeness was used as an index of neighborhood density or the frequency of sound patterns of the nonwords, as wordlikeness ratings are related to the number of real words that share similar sound-patterns in the listener's lexicon (e.g., Bailey \& Hahn, 2001; Masterson et al., 2005). It was hypothesized that repetition ability for less versus more wordlike nonwords would be a better predictor of concurrent phonological awareness and later Grade 1 reading achievement. One previous study found that 4-year-olds' repetition for nonwords rated low in wordlikeness was related to emergent word-reading skills at 5-years (but not for nonwords rated high in wordlikeness) but there was no relationship between concurrent nonword repetition and reading at 5-years of age. Limitations of this previous study that were overcome in the current study were that the 5-year-olds had minimal reading skills and phonological awareness was not examined. To strengthen the argument that nonword repetition indexed variance due to phonological representations, a measure of phonological short-term memory was entered as one of the initial steps in the regression equations or as a covariate in group comparisons. The current study also sought to examine whether a theoretically motivated measure of fall phonological representations and phonological awareness each contributed unique variance to reading achievement five months later, as previous research has been equivocal concerning the inter-relationship between these variables.

\section{Method}

\subsection{Participants}

Of the 100 Grade 1 students who completed testing in the fall, 95 were available to complete word and pseudoword reading tests five months later and were included in the study; 45 participants were female. Participants ranged in age from 70 to 84 months in the fall of Grade 1 (mid-to-late October) at the initial time of testing $(\mathrm{M}=76.15$ months; $\mathrm{SD}=3.37)$. All children were fluent speakers of English and parental reports indicated no history of speech or hearing problems.

\subsection{Time 1 Tasks}

2.2.1 Nonword Repetition. The children were instructed to repeat the nonword exactly as it was pronounced by the voice on the tape recorder and presented via closed-headphones. There were a total of 36 nonwords, consisting of nine nonwords each of 1, 2, 3, and 4 syllable lengths (Gathercole, Willis, Emslie, \& Baddeley, 1991). There were several practice items with feedback. Repetitions were transcribed by a graduate student with training in phonology, using broad phonetic transcription; changes in stress or syllabification were not recorded. Productions with substituted, added, or deleted phonemes were scored as incorrect. Following Dollaghan et al. (1995), vowel modifications typical of everyday speech (e.g., reducing an unstressed, lax vowel to schwa) were scored correct.

Of the 36 nonwords, 11 could be categorized as high on wordlikeness ratings (NWR-high) and 13 as low on wordlikeness ratings (NWR-low), as categorized by Gathercole (1995). These 24 nonwords were 2, 3, and 4 syllables in length. To calculate the scores for each of NWR-high and NWR-low, the proportion correct for each participant at each syllable length was determined and added across the 2, 3, and 4 syllable lengths (a perfect score for either nwr-low or nwr-high would therefore be 3).

2.2.2 Vocabulary. Each participant completed the Peabody Picture Vocabulary Test - Revised (PPVT-R; Dunn \& Dunn 1981), a measure of receptive vocabulary.

2.2.3 Yopp-Singer Test of Phoneme Segmentation. This test required children to "break the word apart" by stating the individual sounds in each orally presented word (Yopp, 1988). The three practice items were given with corrective feedback before the child completed the 22 test items. A liberal scoring criterion was applied such that if the child repeated a consonant sound with a co-articulated, unstressed vowel, the response was scored as correct.

2.2.4 Nonword segmentation. This task was analogous to the Yopp-Singer Test in its presentation and scoring criteria and was presented following that task. Children were required to say the individual sounds for three syllable nonwords. There were three practice items with corrective feedback and 10 test items.

2.2.5 Short-term memory for digits. This task was analogous to the digit span forwards task from the Wechsler Intelligence Scales for Children in its presentation, discontinue rule, and calculation of raw scores (e.g., Wechsler; 1974). Children listened to and repeated sequences of digits, beginning with a 2-digit sequence, and for which there were two trials for each digit length. The test was discontinued when a child missed the two trials for the same digit length. The total number of trials correct comprised the digit span score.

Time 1 and Time 2 Standardized Reading Measures 
2.2.6 Word and pseudoword reading. The Reading subtest of the Wide Range Achievement Test - Revised (WRAT-R; Jastak \& Wilkinson, 1984) was used. This test required children to recognize letters and read individual words. The Word Attack subtest of the Woodcock Reading Mastery Tests- Revised (WRMT-R; Woodcock, 1987) was administered to examine children's ability to read pseudowords.

\subsection{Procedure}

All children were tested individually in a quiet room in their school. Children completed Time 1 tasks in the fall of Grade 1 (mid-to-late October). Time 2 testing occurred five months later in the early spring of Grade 1 (mid-to-late March). Practice items with corrective feedback were presented at the start of the experimental tasks.

\subsection{Results}

As outlined in the introduction, nonword repetition has sometimes been conceptualized and employed as a measure of phonological short-term memory. In order to strengthen the argument that variance accounted for by nonword repetition (NWR) in the dependent variables examined was attributable to phonological representations, a measure of phonological short-term memory was entered as one step in all hierarchical regressions or as a co-variate in the ANCOVAs. A phonological awareness composite score (PA) was used in the analyses and was derived from a principal components analysis with scores from the Yopp-Singer and the nonword segmentation task (Note 1). Table 1 contains the means and standard errors for each measure and Table 2 shows the correlations amongst the variables entered into subsequent regression analyses (Note 2). Given the limited age range, it was not surprising that age did not correlate significantly with any measures (see Table 2) and thus age was not included in any of the following analyses.

2.4.1 Contributions to concurrent phonological awareness. Analyses examining contributions to phonological awareness addressed whether each of vocabulary and NWR would predict unique variance in phonological awareness alongside a measure of phonological short-term memory and whether repetition for less wordlike nonwords would be a better predictor than repetition of more wordlike nonwords. As can be seen in Regression 1 in Table 3, each of phonological short-term memory, vocabulary, and NWR predicted unique variance in phonological awareness. The next two hierarchical regressions in Table 3 showed that when NWR was entered based on type of nonword, only repetition for words low in wordlikeness contributed significant variance beyond the other two variables ( $p=.037$ for NWR-low and $p=.094$ for NWR-high). In summary, the repetition of nonwords low in wordlikeness predicted reliable variance in PA, whereas the repetition of nonwords rated high in wordlikeness did not.

2.4.2 Nonword repetition and later word reading. Previous research has reported that NWR discriminates between children with, or at risk for, reading disabilities and normally achieving peers (e.g., DeBree et al., 2007). The current study sought evidence of the strength of group differences in NWR performance on later word and nonword reading within a normally achieving sample. In order to provide a stringent test of whether group differences on NWR in the fall were related to group differences in reading ability 5 months later, two one-way ANCOVAs were performed. In order to create groups relatively lower and higher in NWR ability, a median split technique was used. This resulted in two groups with 46 and 49 participants, and the groups did not differ on age measured in months $(p=.37 ; M$ age $=75.83, S E=.497$ and $M$ age $=76.45, S E=.482$, for the lower and higher NWR-ability groups respectively). Unless otherwise noted, only those effects that were significant at or beyond the alpha $<.05$ level are reported. The first ANCOVA examined Time 2 (T2) word-reading raw-scores with each of Time 1 (T1) word-reading raw-scores, digit span, and PA scores as covariates. There was a significant effect of the T1 word reading covariate, $F(1,90)=103.25$, T1 PA covariate $F(1,90)=10.54$, and a significant effect of NWR-ability group, $F(1,90)=4.48$ (unadjusted means $=42.46(1.73)$ and $50.06(1.56)$ with corresponding standard WRAT-R scores of $115.46(\mathrm{SE}=3.02)$ and $126.74(\mathrm{SE}=2.92)$, respectively; all participants had standard scores above 90, with the exception of one participant with a standard score of 87). The ANCOVA with T2 word-attack raw-scores as the dependent variable showed a main effect for the T1 word attack covariate $F(1$, $90)=73.08$ and the PA covariate $F(1,90)=4.72$ and the effect of NWR-ability group just failed to reach conventional levels of statistical significance, $F(1,90)=3.88, p=.052$ (unadjusted means $=10.80(1.50)$ and 17.84 (1.59) for NWR-low and -high ability groups, respectively). In sum, there was a robust effect of NWR-ability group on children's word reading and this effect approached conventional levels of statistical significance for children's pseudoword decoding across half the grade 1 school year.

2.4.3 Time 1 contributors to Time 2 reading. Hierarchical regression analyses were undertaken to: 1) examine whether nonword repetition for words low and high in word likeness would each contribute variance to time 2 reading achievement; and 2) test whether measures of phonological representations and PA would each predict unique variance in time 2 reading achievement. Time 1 and Time 2 reading scores were calculated using principal components analyses with word and pseudoword reading raw scores at each respective time of testing. (Note 3) In each of the first 2 analyses predicting T2 reading (see Table 4), the first four steps in the equations 
consisted of the following variables in turn: T1 reading scores, digit span, vocabulary, and PA scores. As can be seen in Regression 1 and 2, T1 reading, vocabulary, and phonological awareness (but not digit span) each accounted for additional variance in T2 reading when entered as the next step into the equation. As can be seen in Regression 1, repetition of words low in wordlikeness did contribute reliable variance to Time 2 reading when added as the fifth step in the equation; however, NWR-high did not ( $\mathrm{p}=.36$; Regression 2). (Note 4)

Finally, the creation of a phonological representations factor was theoretically motivated and represents only the shared variance between nonword repetition and vocabulary. Confirmatory factor analysis was used to create a latent variable (factor) which estimates the shared variance and minimizes both specific and error variance and can be used in further data analyses (LISREL 8.80; Jöreskog, Sörbom, \& Yang Wallentin, 2006; see also Campbell, Rijsdijk, \& Sham, 2007). (Note 5) In Regression 3 (see Table 4), the phonological representations factor accounted for unique variance in T2 reading when entered after each of digit span and phonological awareness. As can also be seen in Regression 3, the unique variance predicted by PA just failed to reach conventional levels of statistical significance in the final equation.

\section{Discussion}

Previous research has supported the view that individual differences in phonological representations, measured using a variety of different tasks, are related to the development of phonological awareness, reading acquisition, and reading disabilities (e.g., Boada \& Pennington, 2006; Elbro et al., 1998; Swan \& Goswami, 1997). Increasingly, it has been suggested that nonword repetition be considered a measure of the quality or structure of phonological representations in lexical memory (e.g., for review see Coady \& Evans, 2008). Toward conceptualizing nonword repetition in this manner, a strength of the current study was that variance related to a measure of phonological short-term memory was removed or covaried in all analyses. It has been proposed that lexical-level phonological representations become more fine-grained or phonemically organized with increasing vocabulary knowledge (e.g., Metsala \& Walley, 1998; Storkel 2002). Within this context, nonword repetition is primarily a measure of children's ability to compile novel representations based on sequences of segments or "chunks" in long-term lexical memory (e.g., Edwards et al., 2004; Jones et al. 2007). In a similar manner, children's ability to access and manipulate phonological information within words for phonological awareness tasks may well depend on this developing saliency of phoneme representations within the mental lexicon (e.g., Fowler, 1991; Metsala, 1999). Thus, it was expected that nonword repetition would be related to phonological awareness beyond variance accounted for by a measure of phonological short-term memory. Insofar as growth in vocabulary drives the segmental organization of phonological representations, vocabulary knowledge was also expected to be related to concurrent phonological awareness. Indeed, results indicated that children's overall nonword repetition performance and vocabulary each contributed to concurrent phonological awareness, alongside the measure of short-term memory. These findings are consistent with previous studies that have demonstrated contributions of vocabulary knowledge and different measures of phonological representations to concurrent phonological awareness, as well as to growth in phonological awareness in young children (e.g., Lonigan et al., 2000; Rvachew, 2006; Torppa et al., 2007).

Previous research has suggested that nonword repetition may be a marker variable in young children at risk for future reading disabilities and has been shown to differ between children with and without reading disabilities (e.g., Catts et al., 2005; DeBree et. al., 2007). In the current study group differences on fall nonword repetition performance were related to later group differences on word-level reading with covariates of fall reading, phonological short-term memory, and phonological awareness. Thus for a sample of normally achieving readers, nonword repetition differentiated the groups on later reading even with this stringent set of covariates.

It has been proposed that repeating nonwords with fewer similarly sounding neighbors would require more autonomy/robustness of individual segments in lexical memory than repetition for wordlike nonwords (e.g., Munson et al., 2005a,b; see also, Masterson et al., 2005). It follows that processing of these less common sound patterns would provide a more sensitive measure of the segmental structure or salience of phonemes within lexical representations. An important contribution of this study was the examination of the contribution to phonological awareness and reading by nonword type. Wordlikeness was used as an index of neighborhood density or the frequency of sound patterns in the nonword stimuli (Bailey \& Hahn, 2001; Masterson et al., 2005) and it was hypothesized that repetition of less wordlike nonwords would be a better predictor of phonological awareness and reading. Indeed, these hypotheses were borne out as nonword repetition for items rated low in wordlikeness predicted unique variance in concurrent phonological awareness and Time 2 reading, whereas repetition for nonwords high in wordlikeness did not.

The finding of a robust relationship between repetition of less common sound sequences and reading processes builds on previous research which reported a strong relationship on spoken word recognition tasks for words from sparse neighborhoods and phonological awareness and reading/reading disabilities (Metsala, 1997b; Metsala et al., 2009). Crowding of lexical neighborhoods has been proposed to drive segmental organization; 
greater variation over a longer developmental time-period may make recognition of words from sparse neighborhoods particularly sensitive to individual differences in lexical representation. The question arises as to why some kids show particular difficulty processing sound patterns that are more uncommon in lexical memory, perhaps particularly those children who have or are at risk for reading difficulties. Some children may know fewer word neighbors for items in both dense and sparse neighborhoods, and this deficit would disproportionately affect the representation of words with fewer neighbors. Segmental reorganization is proposed to disperse throughout the lexicon in a protracted manner, but there may be some critical point in vocabulary development at which time all items become phonemically organized regardless of lexical characteristics (Munson et al. 2005a; see also, Beckman, Munson \& Edwards, 2007; Metsala \& Chisholm, 2010). For children with less rich vocabulary knowledge, phonemic analysis may remain tied to lexical characteristics for a longer period of time. Alternatively, some children may have particular difficulty related to processing less common sound patterns, and vocabulary deficits may be restricted to this area of the mental lexicon. One recent study demonstrated the utility of examining different aspects of vocabulary acquisition in young children in relation to reading acquisition. Lambrecht Smith (2009) reported that children with (versus without) reading disabilities in grade 2 had produced fewer different words and had lower phonological complexity ratings for their word productions at 30 months of age, and suggested that these vocabulary indices may be early markers of reading disabilities. Another possibility is that a third variable, such as the lower level auditory processes indicated in reading difficulties (e.g., Fraser, Goswami, Conti-Ramsden, 2010; Goswami et al., 2002) may cause difficulties for children to both process less common sound patterns and to acquire reading skills in an alphabetic orthography. Future research might examine whether such auditory processing difficulties differentially affect word acquisition for sparse versus dense similarity neighborhoods.

The current study adds to a body of literature which has shown an association between phonological representations and reading. There have been conflicting findings regarding whether this relationship is direct (e.g., Chiappe et al., 2007; Elbro et al., 1998; Metsala, 1997b; Wesseling \& Reitsma, 2001) or is fully mediated by phonological awareness (e.g., Boada \& Pennington, 2006; McBride-Chang, et al., 1997; Metsala et al., 2009). The differences across these studies may reflect various degrees of success at measuring individual differences in phonological representations. In the current study, the shared variance between nonword repetition and vocabulary was utilized as a measure of phonological representations. This combination was theoretically motivated as researchers have proposed that the relationship between these two abilities reflects their shared reliance on phonological representations (e.g., Munson, 2006). In the final regression predicting time 2 word-level reading, this phonological representations factor did predict unique variance beyond that contributed by phonological awareness.

One question for future research might be whether awareness of the phonological structure of language accounts for additional variance in reading beyond the representation of phonological information in the mental lexicon. Simply put, is phonological awareness reducible to phonological representation? This proposal seems congruent with others who have proposed that awareness of segments may not be as important to reading acquisition as the accuracy of the underlying phonological representations or the operations performed on these (e.g., Fowler, 1991; McDougall, Hulme, Ellis, \& Monk, 1994; Swan \& Goswami, 1997). Indeed, within connectionist models of reading, hidden units come to represent knowledge of the connections/consistencies between input (orthography) and output (phonological/semantic) units, without any mechanisms to account for an awareness of phonemes per se (e.g., Plaut, McClelland, Seidenberg, \& Patterson, 1996). In one such model, Brown (1997; see also Metsala, Stanovich, \& Brown, 1998) demonstrated that less segmental representations caused the model to behave in a manner similar to children with reading disabilities. Elbro et al. (1998) suggested that a direct path between phonological representations and reading might be particularly important to the self-teaching mechanism outlined by Share (1995). In the current study, phonological awareness did not overwhelm phonological representations as a predictor of reading, as is sometimes the case for phonological processing variables examined alongside phonological awareness (e.g., Wagner, Torgesen, \& Rashottte, 1994). Currently, there are gaps in the research toward understanding phonological representations in relation to reading acquisition. For example, it is unclear whether the many different measures of phonological representations used in the research comprise a unitary construct, and the stability of such a construct over early childhood needs to be further examined. Findings from the current study suggest that processing of less common sound patterns, and the shared variance between vocabulary and nonword repetition, could be further examined for their utility in better understanding the relationship between reading acquisition and phonological representation.

In summary, the current paper found that the repetition of uncommon sound patterns is predictive of concurrent phonological awareness and later reading ability across grade 1; whereas this relationship did not hold for the repetition for more common sound patters. As well, a Time 1 phonological representations factor had a direct relationship to later reading ability rather than being fully mediated by Time 1 phonological awareness. Future 
research which sheds light on the possible uses of these findings for early detection of reading problems was discussed.

\section{References}

Athony, J.L., Williams, J.M., McDonald, R., \& Francis, D.J. (2007). Phonological processing and emergent literacy in younger and older preschool children. Annals of Dyslexia, 57, 113-137. doi:10.1007/s11881-007-0008-8, http://dx.doi.org/10.1007/s11881-007-0008-8

Bailey, T. M., \& Hahn, U. (2001). Determinants of wordlikeness: Phonotactics or lexical neighborhood? Journal of Memory and Language, 44, 568-591. doi:10.1006/jmla.2000.2756, http://dx.doi.org/10.1006/jmla.2000.2756

Barbosa, T., Miranda, M.C., Santos, R.F., \& Bueno, F.A. (2009). Phonological working memory, phonological awareness and language in literacy difficulties in Brazilian children. Reading and Writing: An Interdisciplinary Journal, 22, 201-218. doi:10.1007/s11145-007-9109-3, http://dx.doi.org/10.1007/s11145-007-9109-3

Beckman, M.E., Munson, B., \& Edwards, J. (2007). The influence of vocabulary growth on developmental changes in types of phonological knowledge. In J. Cole \& J. Hualde (Eds.), Laboratory phonology 9 (pp. 241-264). New York: Mouton de Gruyter.

Boada, R., \& Pennington, B.F. (2006). Deficient implicit phonological representations in children with dyslexia. Journal of Experimental Child Psychology, 95, 153-193. doi:10.1016/j.jecp.2006.04.003, http://dx.doi.org/10.1016/j.jecp.2006.04.003

Boets, B., Wouters, J., van Wieringen, A., \& Ghesquière, P. (2006). Auditory temporal information processing in preschool children at family risk for dyslexia: Relations with phonological abilities and developing literacy skills. Brain and Language, 97, 64-79. doi:10.1016/j.bandl.2005.07.026, http://dx.doi.org/10.1016/j.bandl.2005.07.026

Bonte, M. \& Blomert, L. (2004). Developmental changes in ERP correlates of spoken word recognition during early school years: a phonological priming study. Clinical Neurophysiology. 115, 409-423. doi:10.1016/S1388-2457(03)00361-4, http://dx.doi.org/10.1016/S1388-2457(03)00361-4

Bowey, J.A. (2001). Nonword repetition and young children's receptive vocabulary: A Longitudinal study. Applied Psycholinguistics, 22, 441-469. doi:10.1017/S0142716401003083, http://dx.doi.org/10.1017/S0142716401003083

Bowey, J.A. (2006). Clarifying the phonological processing account of nonword repetition. Applied Psycholinguistics, 27, 548-552. doi:10.1017/S0142716406220393, http://dx.doi.org/10.1017/S0142716406220393

Brady, S., Shankweiler, D., \& Mann, V. (1983). Speech perception and memory coding in relation to reading ability. Journal of Experimental Child Psychology, 35, 345-356. doi:10.1016/0022-0965(83)90087-5, http://dx.doi.org/10.1016/0022-0965(83)90087-5

Brown, G.D.A. (1997). Connectionism, phonology, reading and regularity in developmental dyslexia. Brain and Language, 59, 207-235. doi:10.1006/brln.1997.1817, http://dx.doi.org/10.1006/brln.1997.1817

Bruno, J.L., Manis, F.R., Keating, P., Sperling, A.J., Nakamoto, J., \& Seidenberg, M.S. (2007). Auditory word identification in dyslexic and normally achieving readers. Journal of Experimental Child Psychology, 97, 183-204. doi:10.1016/j.jecp.2007.01.005, http://dx.doi.org/10.1016/j.jecp.2007.01.005

Campbell, D.D., Rijsdijk, F.V., \& Sham, P.C. (2007). Computation of individual latent variables scores from data with multiple missingness patterns. Behavior Genetics, 37, 408-422. doi:10.1007/s10519-006-9123-2, http://dx.doi.org/10.1007/s10519-006-9123-2

Carroll, J.M., \& Snowling, M.J. (2001). The effects of global similarity between stimuli on performance on rime and alliteration tasks. Applied Psycholinguistics, 22, 327-342. doi:10.1017/S0142716401003034, http://dx.doi.org/10.1017/S0142716401003034

Carroll, J.M., \& Snowling, M.J. (2004). Language and phonological skills in children at high risk of reading difficulties. Journal of Child Psychology and Psychiatry, 45, 631-640. doi:10.1111/j.1469-7610.2004.00252.x, http://dx.doi.org/10.1111/j.1469-7610.2004.00252.x

Carroll, J.M., Snowling, M.J., Stevenson, J., \& Hulme, C. (2003). The development of phonological awareness in preschool children. Developmental Psychology, 39, 913-923. doi:10.1037/0012-1649.39.5.913, http://dx.doi.org/10.1037/0012-1649.39.5.913

Catts, H.W., Adlof, S.M., Hogan, S.M., \& Weismer, S.E. (2005). Are specific language impairment and dyslexia distinct disorders? Journal of Speech, Language, and Hearing Research, 48, 1378-1396. doi:10.1044/1092-4388(2005/096), http://dx.doi.org/10.1044/1092-4388(2005/096) 
Chaney, C. (1994). Language development, metalinguistic awareness, and emergent literacy skills of 3-year-old children in relation to social class. Applied Psycholinguistics, 15, 371-394. doi:10.1017/S0142716400004501, http://dx.doi.org/10.1017/S0142716400004501

Chiappe, P., Glaeser, B., \& Ferko, D. (2007). Speech perception, vocabulary, and the development of reading skills in English among Korean-and English-speaking children. Journal of Educational Psychology, 99, 154-166. doi:10.1037/0022-0663.99.1.154, http://dx.doi.org/10.1037/0022-0663.99.1.154

Claessen, M., Heath, S., Fletcher, J., Hogben, J. \& Leitão, S. (2009). Quality of phonological representations: a window into the lexicon? International Journal of Language \& Communication Disorders, 44, 121-144. doi:10.1080/13682820801966317, http://dx.doi.org/10.1080/13682820801966317

Coady, J.A., \& Evans, J.L. (2008). Uses and interpretations of non-word repetition tasks in children with and without specific language impairments (SLI). International Journal of Language Communication Disorders, 43, 1-40. doi:10.1080/13682820601116485, http://dx.doi.org/10.1080/13682820601116485

Cooper, D.H., Roth, F.P., Speece, D.L., \& Schatschneider, C. (2002). The contribution of oral language skills to the development of phonological awareness. Applied Psycholinguistics, 23, 399-416. doi:10.1017/S0142716402003053, http://dx.doi.org/10.1017/S0142716402003053

De Bree, E., Rispens, J., \& Gerrits, E. (2007). Non-word repetition in Dutch children with (a risk of) dyslexia and SLI. Clinical Linguistics \& Phonetics, 21, 935-944. doi:10.1080/02699200701576892, http://dx.doi.org/10.1080/02699200701576892

De Cara, B., \& Goswami, U. (2003). Phonological neighborhood density: effects in a rhyme awareness task in five-year-old children. Journal of Child Language, 30, 695-710. doi:10.1017/S0305000903005725, http://dx.doi.org/10.1017/S0305000903005725

De Jong, P.J., \& van der Leij, A. (1999). Specific contributions of phonological abilities to early acquisition: Results from a Dutch latent variable longitudinal study. Journal of Educational Psychology, 91, 450-476. doi:10.1037/0022-0663.91.3.450, http://dx.doi.org/10.1037/0022-0663.91.3.450

Dollaghan, C.A., Biber, M.E., \& Campbell, T.F. (1993). Constituent syllable effects in a nonsense-word repetition task. Journal of Speech \& Hearing Research, 36, 1051-1054.

Dollaghan, C.A., Biber, M.E., \& Campbell, T.F. (1995). Lexical influences on nonword repetition. Applied Psycholinguistics, $\quad 16, \quad 211-222 . \quad$ doi:10.1017/S0142716400007098, http://dx.doi.org/10.1017/S0142716400007098

Dunn, L.M. \& Dunn, L.M. (1981). Peabody Picture Vocabulary Test-Revised. Circle Pines, Minnesota: American Guidance Service.

Edwards, J., Beckman, M.E., \& Munson, B. (2004). The interaction between vocabulary size and phonotactic probability effects on children's production accuracy and fluency in nonword repetition. Journal of Speech, Language, and Hearing Research, 47, 421-436. doi:10.1044/1092-4388(2004/034), http://dx.doi.org/10.1044/1092-4388(2004/034)

Elbro, C. (1996). Early linguistic abilities and reading development: A review and a hypothesis. Reading and Writing, 8, 453-485. doi:10.1007/BF00577023, http://dx.doi.org/10.1007/BF00577023

Elbro, C., Borstrom, I., \& Peterson, D.K. (1998). Predicting dyslexia from kindergarten: The importance of distinctness of phonological representations of lexical items. Reading Research Quarterly, 31, 36-60. doi:10.1598/RRQ.33.1.3, http://dx.doi.org/10.1598/RRQ.33.1.3

Elbro, C., \& Jensen, M.N. (2005). Quality of phonological representations, verbal learning, and phoneme awareness in dyslexic and normal readers. Scandinavian Journal of Psychology, 46, 375-384. doi:10.1111/j.1467-9450.2005.00468.x, http://dx.doi.org/10.1111/j.1467-9450.2005.00468.x

Fowler, A.E. (1991). How early phonological development might set the stage for phoneme awareness. In S.A. Brady \& D.P. Shankweiler (Eds.), Phonological processes in literacy: A tribute to Isabelle Y. Liberman (pp. 97-117). Hillsdale, New Jersey: Erlbaum.

Fraser, J., Goswawmi, U., Conti-Ramsden, G. (2010). Dyslexia and Specific Language Impairment: The Role of Phonology and Auditory Processing. Scientific Studies of Reading, 14, 8-29. doi:10.1080/10888430903242068, http://dx.doi.org/10.1080/10888430903242068

French, L.M., \& O’Brien, I. (2008). Phonological memory and children's second language grammar learning. Applied Psycholinguistics, 29, 463-487. doi:10.1017/S0142716408080211, http://dx.doi.org/10.1017/S0142716408080211 
Foy, J.G., \& Mann, V.A. (2001). Does strength of phonological representations predict phonological awareness in preschool children? Applied Psycholinguistics, 22, 301-325. doi:10.1017/S0142716401003022, http://dx.doi.org/10.1017/S0142716401003022

Foy, J.G., \& Mann, V.A. (2003). Home literacy environment and phonological awareness: Differential effects for phoneme awareness and rhyme awareness. Applied Psycholinguistics, 24, 59-88. doi:10.1017/S0142716403000043, http://dx.doi.org/10.1017/S0142716403000043

Garlock, V.M., Walley, A.C. \& Metsala, J.L. (2001). Age-of-acquisition, word frequency and neighborhood density effects on spoken word recognition: Implications for the development of phoneme awareness and early reading ability. Journal of Memory and Language, 45, 468-492. doi:10.1006/jmla.2000.2784, http://dx.doi.org/10.1006/jmla.2000.2784

Gathercole, S.E. (1995). Is nonword repetition a test of phonological memory or long-term knowledge? It all depends on the nonwords. Memory \& Cognition, 23, 83-94. doi:10.3758/BF03210559, http://dx.doi.org/10.3758/BF03210559

Gathercole, S.E., Willis, C., Emslie, H., \& Baddeley, A.D. (1991). The influences of number of syllables and wordlikeness on children's repetition of nonwords. Applied Psycholinguistics, 12, 349-367. doi:10.1017/S0142716400009267, http://dx.doi.org/10.1017/S0142716400009267

Gathercole, S.E., Willis, C., Emslie, H., \& Baddeley, A.D. (1992). Phonological memory and vocabulary development during the early school years: a longitudinal study. Developmental Psychology, 28, 887-898. doi:10.1037//0012-1649.28.5.887, http://dx.doi.org/10.1037//0012-1649.28.5.887

Gijsel, M.A.R., Bosman, A.M.T., \& Verhoeven, L. (2006). Kindergarten risk factors, cognitive factors, and teacher judgments as predictors of early reading in Dutch. Journal of Learning Disabilities, 39, 558-571. doi:10.1177/00222194060390060701, http://dx.doi.org/10.1177/00222194060390060701

Goswami, U., Thomson, J., Richardson, U., Stainthorp, R., Hughes, D., Rosen, S., \& Scott, S.K. (2002). Amplitude envelope onsets and developmental dyslexia: a new hypothesis. Proceedings of the National Academy of Sciences of the United States of America, 99, 10911-10916. doi:10.1073/pnas.122368599, http://dx.doi.org/10.1073/pnas.122368599

Jastak, S., \& Wilkinson, G.S. (1984). The Wide Range Achievement Test-Revised. Jastak Associates, Wilmington, DE. Jones, G., Gobet, F., \& Pine, J.M. (2007). Linking working memory and long-term memory: A computational model of the learning of new words. Developmental Science, 10, 853-873. doi:10.1111/j.1467-7687.2007.00638.x, http://dx.doi.org/10.1111/j.1467-7687.2007.00638.x

Jöreskog, K.G., Sörbom, D. \& Yang Wallentin, F. (2006). Latent variable scores and observational residuals. Scientific Software International. [Online] Available: http://www.ssicentral.com/lisrel/techdocs/obsres.pdf (July, 2008).

Jusczyk, P.W. (1993). From general to language-specific capacities: The WRAPSA model of how speech perception develops. Journal of Phonetics, 21, 3-28.

Jusczyk, P.W. (1995). Language acquisition: Speech sounds and the beginning of phonology. In J.L. Miller \& P.D. Eimas (Eds.), Speech, language, and communication (pp.263-301). San Diego, CA: Academic Press. doi:10.1016/B978-012497770-9/50010-8, http://dx.doi.org/10.1016/B978-012497770-9/50010-8

Lambrecht Smith, S. (2009). Early phonological and lexical markers of reading disabilities. Reading and Writing. An Interdisciplinary Journal, 22, 25-40. doi:10.1007/s11145-007-9101-y, http://dx.doi.org/10.1007/s11145-007-9101-y

Lonigan, C. J. (2007). Vocabulary development and the development of phonological awareness skills in preschool children. In R. K. Wagner, A. E. Muse, \& K. R. Tannenbaum (Eds.), Vocabulary acquisition: Implications for reading comprehension (pp. 15-31). New York: The Guilford Press.

Lonigan, C.J., Burgess, S.R., \& Anthony, J.L. (2000). Development of emergent literacy and early reading skills in preschool children: Evidence from a latent-variable longitudinal study. Developmental Psychology, 36, 596-613. doi:10.1037//0012-1649.36.5.596, http://dx.doi.org/10.1037//0012-1649.36.5.596

Luce, P. A., \& Pisoni, D. B. (1998). Recognizing spoken words in the mental lexicon: The neighborhood activation model. Ear and Hearing, 19, 1-36. doi:10.1097/00003446-199802000-00001, http://dx.doi.org/10.1097/00003446-199802000-00001

Masterson, J., Laxon, V., Carnegie, E., Wright, S., Horslen, J. (2005). Nonword recall and phonemic discrimination in four- to six-year-old children. Journal of Research in Reading, 28, 183-201. doi:10.1111/j.1467-9817.2005.00262.x, http://dx.doi.org/10.1111/j.1467-9817.2005.00262.x 
McBride-Chang, C., Wagner, R.K. \& Chang, L. (1997). Growth modeling of phonological awareness. Journal of Educational Psychology, 89, 621-630. doi:10.1037/0022-0663.89.4.621, http://dx.doi.org/10.1037/0022-0663.89.4.621

McDougall, S., Hulme, C., Ellis, A., \& Monk, A. (1994). Learning to read: The role of short-term memory and phonological skills. Journal of Experimental Child Psychology, 58, 112-133. doi:10.1006/jecp.1994.1028, http://dx.doi.org/10.1006/jecp.1994.1028

McDowell, K.D., Lonigan, C.J., \& Goldstein, H. (2007). Relations among socioeconomic status, age, and predictors of phonological awareness. Journal of Speech, Language, and Hearing Research, 50, 1079-1092. doi:10.1044/1092-4388(2007/075), http://dx.doi.org/10.1044/1092-4388(2007/075)

Metsala, J.L. (1997a). An examination of word frequency and neighborhood density in the development of spoken word recognition. Memory and Cognition, 25, 47-56. doi:10.3758/BF03197284, http://dx.doi.org/10.3758/BF03197284

Metsala, J.L. (1997b). Spoken word recognition in reading disabled children. Journal of Educational Psychology, 89, 159-169. doi:10.1037//0022-0663.89.1.159, http://dx.doi.org/10.1037//0022-0663.89.1.159

Metsala, J. L. (1999). Young children's phonological awareness and nonword repetition as a function of vocabulary development. Journal of Educational Psychology, 91, 3-19. doi:10.1037//0022-0663.91.1.3, http://dx.doi.org/10.1037//0022-0663.91.1.3

Metsala, J.L. (2011). Lexical reorganization and the emergence of phonological awareness. In S.B. Neuman \& D.K. Dickenson (Eds), Handbook of Early Literacy Research, V. 3, Guilford Press, New York; NY.

Metsala, J.L., \& Chisholm, G. (2010). The influence of lexical status and neighborhood density on children's nonword repetition. Applied Psycholinguistics, 31, 489-506. doi:10.1017/S0142716410000081, http://dx.doi.org/10.1017/S0142716410000081

Metsala, J.L., Stanovich, K.E., \& Brown, G.D.A. (1998). Regularity effects and the phonological deficit model of reading disabilities: A meta-analytic review. Journal of Educational Psychology, 90, 279-293. doi:10.1037//0022-0663.90.2.279, http://dx.doi.org/10.1037//0022-0663.90.2.279

Metsala, J.L., Stavrinos, D., \& Walley, A.C. (2009). Children's spoken word recognition and contributions to phonological awareness and nonword repetition: A one-year follow-up. Applied Psycholinguistics, 30, 101-121. doi:10.1017/S014271640809005X, http://dx.doi.org/10.1017/S014271640809005X

Metsala , J.L., \& Walley, A.C. (1998). Spoken vocabulary growth and the segmental restructuring of lexical representations: Precursors to phonemic awareness and early reading ability. In J.L. Metsala \& L.C. Ehri (Eds.), Word recognition in beginning literacy (pp. 89-120). Mahwah, New Jersey: Erlbaum.

Munson, B. (2006). Nonword repetition and levels of abstraction in phonological knowledge. Applied Psycholinguistics, 27, 577-581. doi:10.1017/S0142716406290398, http://dx.doi.org/10.1017/S0142716406290398

Munson, B., Edwards, J., \& Beckman, M.E. (2005a). Relationships between nonword repetition accuracy and other measures of linguistic development in children with phonological Disorders. Journal of Speech, Language, and Hearing Research, 48, 61-78. doi:10.1044/1092-4388(2005/006), http://dx.doi.org/10.1044/1092-4388(2005/006)

Munson, B., Kurtz, B., \& Windsor, J. (2005b). The influence of vocabulary size, phonotactic probability, and wordlikeness on nonword repetitions of children with and without specific language impairment. Journal of Speech, Language, and Hearing Research, 48, 1033-1047. doi:10.1044/1092-4388(2005/072), http://dx.doi.org/10.1044/1092-4388(2005/072)

Ottem, E.J., Lian, A., \& Karlson, P.J. (2007). Reasons for the growth of traditional memory span across age. European Journal of Cognitive Psychology, 19, 233-270. doi:10.1080/09541440600684653, http://dx.doi.org/10.1080/09541440600684653

Plaut, D. C., McClelland, J. L., Seidenberg, M. S., \& Patterson, K. (1996). Understanding normal and impaired word reading: Computational principles in quasi-regular domains. Psychological Review, 103, 56-115. doi:10.1037//0033-295X.103.1.56, http://dx.doi.org/10.1037//0033-295X.103.1.56

Roberts, T.A. (2005). Articulation accuracy and vocabulary size contributions to phonemic awareness and word reading in English language learners. Journal of Educational Psychology, 97, 601-616. doi:10.1037/0022-0663.97.4.601, http://dx.doi.org/10.1037/0022-0663.97.4.601

Roodenrys, S. \& Stokes, J. (2001) Serial recall and nonword repetition in reading disabled children. Reading and Writing, 14, 379-394. doi:10.1023/A:1011123406884, http://dx.doi.org/10.1023/A:1011123406884 
Rvachew, S. (2006). Longitudinal predictors of implicit phonological awareness skills. American Journal of Speech-Language Pathology, 15, 165-176. doi:10.1044/1058-0360(2006/016), http://dx.doi.org/10.1044/1058-0360(2006/016)

Rvachew, S., \& Grawburg, M. (2006). Correlates of phonological awareness in preschoolers with speech sound disorders. Journal of Speech, Language, and Hearing Research, 49, 74-87.

Schwarz, I.C., Burnham, D., \& Bowey, J.A. (2006). Phoneme sensitivity and vocabulary size in $21 / 2$ 3 -year-olds. Proceedings of the $11^{\text {th }}$ Australian International Conference on Speech Science \& Technology, 142-147.

Sénéchal, M., \& LeFevre J. (2002). Parental involvement in the development of children's reading skill: A five-year longitudinal study. Child Development, 73, 445-460. doi:10.1111/1467-8624.00417, http://dx.doi.org/10.1111/1467-8624.00417

Sénéchal, M., Oullette, G., \& Young, L. (2004). Testing the concurrent and predictive relations among articulation accuracy, speech perception, and phoneme awareness. Journal of Experimental Child Psychology, 89, 242-269. doi:10.1016/j.jecp.2004.07.005, http://dx.doi.org/10.1016/j.jecp.2004.07.005

Share, D.L. (1995). Phonological recoding and self-teaching: sine qua non of reading acquisition. Cognition, 55 , 151-218. doi:10.1016/0010-0277(94)00645-2, http://dx.doi.org/10.1016/0010-0277(94)00645-2

Silvén, M., Niemi, P., \& Voeten, M.J.M. (2002). Do maternal interaction and early language predict phonological awareness in 3-to 4-year-olds? Cognitive Development, 17, 1133-1155. doi:10.1016/S0885-2014(02)00093-X, http://dx.doi.org/10.1016/S0885-2014(02)00093-X

Smith, B.L., McGregor, K.K., \& Demille, D. (2006). Phonological development in lexically precocious 2-year-olds. Applied Psycholinguistics, 27, 355-375. doi:10.1017/S0142716406060310, http://dx.doi.org/10.1017/S0142716406060310

Smith, S.D., Pennington, B.F., Boada, R., \& Shriberg, L.D. (2005). Linkage of speech sound disorder to reading disability loci. Journal of Child Psychology and Psychiatry, 46, 631-640. doi:10.1111/j.1469-7610.2005.01534.x, http://dx.doi.org/10.1111/j.1469-7610.2005.01534.x

Snowling, M. (1981). Phonemic deficits in developmental dyslexia, Psychological Research, 43, 219-234. doi:10.1007/BF00309831, http://dx.doi.org/10.1007/BF00309831

Snowling, M., Chiat, S., \& Hulme, C. (1991). Words, nonwords and phonological processes: Some comments on Gathercole, Willis, Emslie and Baddeley. Applied Psycholinguistics, 12, 369-373. doi:10.1017/S0142716400009279, http://dx.doi.org/10.1017/S0142716400009279

Storkel, H.L. (2002). Restructuring of similarity neighbourhoods in the developing mental lexicon. Journal of Child Language, 29. 251-274. doi:10.1017/S0305000902005032, http://dx.doi.org/10.1017/S0305000902005032

Swan, D. \& Goswami, U. (1997). Phonological awareness deficits in developmental dyslexia and the phonological representations hypothesis. Journal of Experimental Child Psychology, 66, 18-41. doi:10.1006/jecp.1997.2375, http://dx.doi.org/10.1006/jecp.1997.2375

Swingley, D. \& Aslin, R. (2002). Lexical neighborhoods and the word-form representations of 14-month-olds. Psychological Science, 13, 480-484. doi:10.1111/1467-9280.00485, http://dx.doi.org/10.1111/1467-9280.00485

Tabachnick, B. G., \& Fidell, L. S. (2001). Using multivariate statistics, Fourth Edition. Toronto: Allyn \& Bacon. Thomas, E., \& Sénéchal, M. (2004). Long-term association between articulation quality and phoneme sensitivity: A study from age 3 to age 8. Applied Psycholinguistics, 25, 513-541. doi:10.1017/S0142716404001250, http://dx.doi.org/10.1017/S0142716404001250

Torgesen, J.K., \& Burgess, S.R. (1998) Consistency of reading-related phonological processes throughout early childhood: Evidence from longitudinal-correlational and instructional studies. In J.L. Metsala \& L.C. Ehri (Eds.), Word recognition in beginning literacy (pp. 89-120). Mahwah, New Jersey: Erlbaum.

Torppa, M., Poikkeus, A.M., Laakso, M.L., Tolvanen, A., Leskinen, E., \& Leppänen, P.H.T. (2007). Modeling the early paths of phonological awareness and factors supporting its development in children with and without familiar risk of dyslexia. Scientific Studies of Reading, 11, 73-103. doi:10.1080/10888430709336554, http://dx.doi.org/10.1080/10888430709336554

Vitevitch, M.S. \& Luce, P.A. (1998). When words compete: Levels of processing in perception of spoken words. Psychological Science, 9, 325-329. doi:10.1111/1467-9280.00064, http://dx.doi.org/10.1111/1467-9280.00064

Wagner, R.K., Torgesen, J.K., Laughon, P., Simmons, K., \& Rashotte, C.A. (1993). Development of young readers' phonological processing abilities. Journal of Educational Psychology. 85, 83-103. doi:10.1037//0022-0663.85.1.83, http://dx.doi.org/10.1037//0022-0663.85.1.83 
Wagner, R.K., Torgesen, J.K. \& Rashotte, C.A. (1994). Development of reading-related phonological processing abilities: New evidence of bidirectional causality from a latent variable longitudinal study. Developmental Psychology, 30, 73-87. doi:10.1037//0012-1649.30.1.73, http://dx.doi.org/10.1037//0012-1649.30.1.73

Walley, A.C. (1993). The role of vocabulary development in children's spoken recognition and segmentation ability. Developmental Review, 13, 286-350. doi:10.1006/drev.1993.1015, http://dx.doi.org/10.1006/drev.1993.1015

Wechsler, D. (1974). Wechsler Intelligence Scale for Children-Revised. New York: Psychological Corporation.

Wesseling, R., \& Reitsma, P. (2001). Preschool phonological representations and development of reading skills. Annals of Dyslexia, 51, 203-229. doi:10.1007/s11881-001-0011-4, http://dx.doi.org/10.1007/s11881-001-0011-4

Woodcock, R. W. (1987). Woodcock reading mastery tests-Revised. Circle Pines, MN: American Guidance Service.

Yopp, H.K. (1988). The validity and reliability of phonemic awareness tests, Reading Research Quarterly, 23, 159-177. doi:10.2307/747800, http://dx.doi.org/10.2307/747800

\section{Notes}

Note 1 . The principal component accounted for $83.91 \%$ of the total variance and both variables loaded at 916 .

Note 2. Variables entered into regression analyses were of acceptable limits for skewness and kurtosis, with the exception of the time 1 reading measures (Tabachnick \& Fidell, 2001). Simple transformations did not eliminate this problem. As the T1 reading composite was strongly correlated with the T2 reading composite $(\mathrm{r}=.81)$, it was retained as is in order to provide a stringent test of hypotheses concerning the prediction of T2 reading.

Note 3. For Time 1 reading, the principal component accounted for $94.48 \%$ of the total variance and both variables loaded at .967 . For Time 2 reading, the principal component accounted for $96.21 \%$ of the total variance and both variables loaded at 981 .

Note 4. To ensure that NWR-low was not a better predictor simply because some children were at or near ceiling on repeating words high in wordlikeness, parallel regressions were performed excluding children who made 1 or no errors on NWR-high. These regressions $(\mathrm{N}=76)$ showed the same pattern of significant contributions to time 2 reading for NWR-high $(\mathrm{p}=.232)$ and NWR-low $(\mathrm{p}=.017)$.

Note 5. The standardized regression coefficient from the phonological representations factor to nwr was .68 and from the phonological representations factor to vocabulary was .73 .

Table 1. Means and Standard Errors for Major Variables in the Study

\begin{tabular}{lll}
\hline Variable & $M$ & $S D$ \\
Time 1 measures & & \\
\hline PPVT- R (SS) & 99.34 & 16.72 \\
NWR & 26.44 & 4.23 \\
Digit Span & 7.16 & 2.01 \\
Yopp-Singer Test of & & \\
Phoneme Segmentation & 9.28 & 6.80 \\
& & \\
Nonword Segmentation & 4.09 & 3.25 \\
WRAT-R (RS) & 34.91 & 12.22 \\
dWRAT-R (SS) & 111.89 & 19.74 \\
WRMT-R (RS) & 5.28 & 8.59 \\
Time 2 measures & & \\
WRAT-R (RS) & 46.55 & 11.95 \\
WRAT-R (SS) & 121.25 & 21.14 \\
WRMT-R (RS) & 14.51 & 11.26 \\
\hline
\end{tabular}

Note. SS- Standard score; RS - raw score; PA - phoneme awareness; NWR - nonword repetition; WRAT-R Wide Range Achievement Test- Revised, Word Reading subtest; WRMT-R - Woodcock Reading Mastery Tests Revised; Word Attack subtest. 
Table 2. Correlations between major variables in regressions

\begin{tabular}{|c|c|c|c|c|c|c|c|c|c|}
\hline & $\begin{array}{l}\text { Vocabu } \\
\text { lary }\end{array}$ & $\begin{array}{l}\text { Digit } \\
\text { Span }\end{array}$ & NWR & $\begin{array}{l}\text { NWR } \\
\text {-High }\end{array}$ & $\begin{array}{l}\text { NWR } \\
\text {-Low }\end{array}$ & $\begin{array}{l}\text { PR-Fac } \\
\text { tor }\end{array}$ & PA & $\begin{array}{l}\text { T1 } \\
\text { Rdg }\end{array}$ & $\begin{array}{l}\text { T2 } \\
\text { Rdg }\end{array}$ \\
\hline Age & .065 & .078 & .054 & .052 & .060 & .156 & .137 & .166 & .084 \\
\hline Vocabulary & & $.274 *$ & $.510^{*}$ & $.389^{*}$ & $.386^{*}$ & $.863^{*}$ & $.432 *$ & $.437^{*}$ & $.481 *$ \\
\hline Digit Span & & & $.351^{*}$ & $.249^{\wedge}$ & $.347 *$ & $.406^{*}$ & $.404 *$ & $.417^{*}$ & $.434^{*}$ \\
\hline NWR & & & & $.729 *$ & $.817^{*}$ & $.818^{*}$ & $.441 *$ & $.394 *$ & $.490^{*}$ \\
\hline NWR-High & & & & & $.485^{*}$ & $.610^{*}$ & $.357 *$ & $.323 *$ & $.376^{*}$ \\
\hline NWR-Low & & & & & & $.678^{*}$ & $.420^{*}$ & $.334 *$ & $.416^{*}$ \\
\hline PR-Factor & & & & & & & $.593 *$ & $.572 *$ & $.667^{*}$ \\
\hline PA & & & & & & & & $.565^{*}$ & $.624^{*}$ \\
\hline T1 Rdg & & & & & & & & & $.810^{*}$ \\
\hline
\end{tabular}

Note. All measures are from Time 1 (fall) testing with the exception of T2 Rdg.

Vocab = PPVT-R, standard score; NWR - nonword repetition for 36 nonwords; NWR-low - nonword repetition for nonwords categorized as low in wordlikeness; NWR-high - nonword repetition for nonwords categorized as high in wordlikeness; PR-factor - phonological representations latent variable from the observed variables of NWR and vocabulary; PA - phonological awareness composite scores; T1 Rdg - Time 1 reading composite scores; T2 Rdg - Time 2 reading composite scores. ${ }^{\wedge} \mathrm{p}<.05 ; * \mathrm{p}<.01$

Table 3. Hierarchical Regression Analyses predicting Time 1 PA

\begin{tabular}{llllll}
\hline Step variable & $R^{2}$ & $R^{2}$ change & Final $\beta$ & $d f$ & sig.
\end{tabular}

Dependent Variable - Phonological Awareness (PA)

Regression 1.

$\begin{array}{llllll}\text { 1. Digit Span } & .163 & & .254 & 93 & * \\ \text { 2. NWR } & .262 & .098 & .255 & 92 & * \\ \text { 3. Vocabulary } & .309 & .047 & .214 & 91 & *\end{array}$

Regression 2.

1. Digit Span

2. Vocabulary

.163

.277

.311

.114

.034

.251

.284

.208

93

92

3. NWR-low

.163

.277

.299

.114

.283

.294

.174

sig.

Regression 3.

2. Vocabulary

91

3. NWR-high

Note. All measures are from Time 1 (fall) testing. PA - phonological awareness composite scores; Vocabulary $=$ PPVT-R, standard score; NWR - nonword repetition for 32 nonwords; NWR-low - nonword repetition for nonwords categorized as low in wordlikeness; NWR-high - nonword repetition for nonwords categorized as high in wordlikeness; PR-factor - phonological representations latent variable from the observed variables of NWR and vocabulary, as described in text; * $p<.05$ 
Table 4. Hierarchical Regression Analyses predicting Time 2 Reading

Step variable $\mathrm{R}^{2} \quad \mathrm{R}^{2}$ change(sig) Final $\beta$ df Final $p$

Dependent Variable - Time 2 Reading

Regression 1.

1. T1 Reading

2. Digit Span

.698

.707

3. Vocabulary

.721

4. PA

.743

5. NWR-low

$$
.009
$$

$.016^{*}$

$.022^{* *}$

$.011^{*}$

.698

.707

.721

.743

.745

5. NWR-high

Regression 3

1. T1 Reading

2. Digit Span

3. PA

4. $P R$
.698

.707

.737

.763

.009
$.016^{*}$
$.022^{* *}$
.002

.009

$.030^{* *}$

$.026^{* *}$
.665

.031

.060

.163

.123

.665

.031

.060

.163

.055

.623

.031

.134

.218

$93 * *$
92
91
$90 *$
$89 *$

93 **

92

91

90 *

89

Note. All predictor variables are Time 1 measures. T2 Reading -- Time 2 reading composite scores. T1 Reading - Time 1 reading composite scores. Vocabulary = PPVT-R, standard score; NWR - nonword repetition for 32 nonwords; NWR-low - nonword repetition for nonwords categorized as low in wordlikeness; NWR-high nonword repetition for nonwords categorized as high in wordlikeness; PA - phonological awareness composite scores; PR-factor - phonological representations latent variable from the observed variables of NWR and vocabulary, as described in text; ${ }^{*} p<.05 ;{ }^{* *} \mathrm{p}<.005 ;{ }^{\wedge} \mathrm{p}<.07$ 